\title{
Age and Geographical Distribution in Families with BRCA1/BRCA2 Mutations in the Slovak Republic
}

\author{
Sona Ciernikova, Miroslav Tomka, Michal Kovac, Viola Stevurkova, Vladimir Zajac \\ Cancer Research Institute, Slovak Academy of Sciences, Slovak Republic
}

Key words: breast and ovarian cancer, $B R C A 1, B R C A 2$, Slovak HBOC families

Corresponding author: Vladimir Zajac, Department of Cancer Genetics, Cancer Research Institute, Slovak Academy of Sciences, Vlarska 7, 83391 Bratislava, Slovakia, phone +421 259327 317; fax +421 259327250 ,

e-mail:vladimir.zajac@savba.sk

Submitted: 15 December 2005

Accepted: 31 December 2005

\begin{abstract}
Molecular diagnostics of hereditary breast and/or ovarian cancer is mainly based on detection of BRCAI and BRCA2 germline mutations in suspected families. The aim of the study was to determine the frequency, age and geographical distribution in 130 Slovak hereditary breast and ovarian cancer (HBOC) families diagnosed within the years 2000-2004. Mutation screening was performed by single-strand conformation polymorphism (SSCP), heteroduplex analysis (HDA) and sequencing of PCR products showing an abnormal migration pattern. Twenty of 130 (15.6\%) HBOC suspected families were found to carry mutations in BRCA1 or BRCA2 genes. The glossary data from the National Cancer Registry of Slovakia (NCRS) were compared with the results from HBOC suspected kindreds. Age distribution of breast cancer onset in our study group showed the highest proportion of onset in HBC families within the $5^{\text {th }}$ decade of life, while NCRS reports at least a ten year later onset. These findings confirmed that cases of breast cancer under 50 years of age can be used as one of the principal criteria to assign a family as a hereditary breast and/or ovarian cancer kindred. In contrast with unselected ovarian cancer cases, about $75 \%$ of all HOC index cases were diagnosed between 40 and 49 years of age. To study the geographical distribution of hereditary breast and/or ovarian cancer, Slovakia was divided into three parts. The distribution of $\mathrm{HBOC}$ suspected families approximately follows this division, with an increasing number in the western area of the country.
\end{abstract}

\section{Introduction}

Breast cancer is the most common malignancy affecting women in the Slovak Republic, accounting for 1,858 and 1,827 newly diagnosed breast cancer cases in years 2000 and 2001, respectively (World Standardized Rates 47.0/100,000 and 46.1/100,000). The complete data from NCRS show that it is also the leading cause of cancer-related mortality among Slovak women, the proportion being $15.1 \%$ of all cancer cases.
NCRS was created as one of the first in Central and Eastern Europe and contains 30-year-old data about newly diagnosed cancer patients of all types. According to NCRS evidence, 414 and 449 newly diagnosed cases of ovarian cancer were reported in years 2000 and 2001 (World Standardized Rates: 10.9/100,000 and $11.4 / 100,000)$. They represent $4.3 \%$ of all cancer deaths, and ovarian cancer is therefore the most frequent cause of death of all gynaecological malignancies. 
A family history of breast and/or ovarian cancer is the most significant risk factor for developing the disease. An estimated 5-10\% of all breast and ovarian cancer cases are hereditary in nature [1]. The search for genes associated with hereditary susceptibility to breast or ovarian cancer has been facilitated by the study of large kindreds with multiple affected individuals, and has led to the identification of several susceptibility genes, of which BRCA1 (MIM 1 13705) and BRCA2 (MIM 600185) are the most penetrant. Carriers of germline mutations in these genes have a $50-85 \%$ lifetime risk of breast cancer and a $15-45 \%$ risk of developing ovarian cancer during their lifetime $[2,3]$. It was estimated that the combination of BRCA1/BRCA2 mutations was responsible for approximately $80 \%$ of all $\mathrm{HBOC}$ families [4,5]. More recent estimates put this risk at about $30 \%$ and other low penetrance candidate genes involved in breast cancer susceptibility, CHEK2, ATM, TP53 and PTEN, have been identified [6,7].

Here we aim to determine the frequency, age and geographical distribution of families carrying BRCA1/BRCA2 mutations within our collection of Slovak HBOC suspected kindreds. For this purpose, we have performed mutation screening of the entire coding region of $B R C A 1$ and the first 16 exons of BRCA2 in 130 Slovak HBOC suspected families. Knowledge about $\mathrm{HBOC}$ families has been compared with the overall distribution of breast and ovarian cancer cases in 2001 and 2002, reported by NCRS.

\section{Patients and methods}

The collection of Slovak HBOC suspected families was obtained from the National Cancer Institute, the Centre of Clinical Genetics of the Faculty Hospital (Bratislava) and the departments of medical genetics of hospitals from all over the Slovak Republic. Informed consent was required prior to testing. Families having affected women were divided into potentially average, moderate or high risk of developing breast and/or ovarian cancer due to their family history. Potentially average-risk $\mathrm{HBOC}$ suspected families were defined by the presence of one breast cancer diagnosed under the age of 40 , breast and ovarian cancer in the same individual at any age and bilateral breast cancer. Moderate risk was defined as two breast or ovarian cancer cases among first- and second-degree relatives (index case included) from the same ancestral lineage or a combination of breast and ovarian cancer among first-degree relatives. Families with high risk were characterized by the presence of at least three first- and second-degree affected relatives (index case included) on the same lineage of the HBOC suspected proband.

\section{Mutation screening}

Genomic DNA was extracted from peripheral blood lymphocytes using QIAamp DNA blood kit (Qiagen, Hilden, Germany). All exons including intron-exon boundaries of BRCA1 and the first 16 exons of BRCA2 were amplified by $P C R$ using the set of primers according to Wagner et al. [8]. Mutation screening methods included SSCP and HDA as previously described [9]. Fragments showing aberrant band profiling were sequenced on the $A B I$ PRISM ${ }^{\circledR} 3100$ Avant Genetic Analyzer (Applied Biosystems, Foster City, CA, USA).

\section{Results}

The study revealed that 20 of 130 (15.6\%) HBOC suspected families carry mutations in BRCA1/BRCA2 genes using standard molecular techniques that included SSCP, HDA and subsequent automatic sequencing of $P C R$ products with aberrant mobility. The efficiency of BRCA1/BRCA2 mutation detection in relation to the selection criteria is summarized in Table 1. Most analysed kindreds (80) were classified in the high-risk group, 40 families belong to the group with moderate risk and a relatively small number (10) was at average risk for genetic predisposition. The highest detection rate (17.5\%) of disease-causing BRCA $1 / 2$ alleles was identified in the high-risk group of families with at least 3 breast or ovarian cancer cases. The majority (85\%) of all detected mutations in our collection were attributable to BRCA1.

Table 1. The efficiency of mutation detection in relation to selection criteria

\begin{tabular}{lcccc}
\hline Selection Criteria & Number of Families & BRCA1 mutation (\%) & BRCA2 mutation (\%) & Overall mutation (\%) \\
\hline average-risk HBOC & 10 & $1(10 \%)$ & $1(10 \%)$ \\
\hline moderate-risk HBOC & 40 & $4(10 \%)$ & $1(2.5 \%)$ & $2(2.5 \%)$ \\
\hline high-risk HBOC & 80 & $12(15 \%)$ & 3 & $14(17.5 \%)$ \\
\hline total & 130 & 17 & 20 \\
\hline
\end{tabular}


Table 2. Age distribution in Slovak HBC and HOC suspected families

\begin{tabular}{lcccc}
\hline \multirow{2}{*}{ Decade } & \multicolumn{2}{c}{ HBC families } & \multicolumn{2}{c}{ HOC families } \\
\cline { 2 - 5 } & overall & with mutation & overall & with mutation \\
\hline $15-29$ & $9(8 \%)$ & $1(9 \%)$ & $0(0 \%)$ & - \\
\hline $30-39$ & $30(26.5 \%)$ & $2(18.2 \%)$ & $1(5.9 \%)$ & - \\
\hline $40-49$ & $52(46 \%)$ & $4(36.4 \%)$ & $13(76.5 \%)$ & $5(55.5 \%)$ \\
\hline $50-59$ & $20(17.7 \%)$ & $4(36.4 \%)$ & $3(17.6 \%)$ & $4(44.5 \%)$ \\
\hline $60-69$ & $2(1.8 \%)$ & - & - & - \\
\hline total $(100 \%)$ & 113 & 11 & 17 & 9 \\
\hline
\end{tabular}

Table 3. Age distribution in unselected breast and ovarian cancer cases according to NCRS*

\begin{tabular}{lcccc}
\hline \multirow{2}{*}{ Decade } & \multicolumn{2}{c}{ Breast Cancer Cases } & \multicolumn{2}{c}{ Ovarian Cancer Cases } \\
\cline { 2 - 5 } & \multicolumn{2}{c}{ NCRS* } & $2000(\%)$ & NCRS* \\
\cline { 2 - 5 } & $2000(\%)$ & $7(0.4 \%)$ & $17(4.1 \%)$ & $22(4.9 \%)$ \\
\hline $15-29$ & $4(0.2 \%)$ & $98(5.4 \%)$ & $33(8 \%)$ & $17(3.8 \%)$ \\
\hline $30-39$ & $100(5.4 \%)$ & $365(20 \%)$ & $84(20.3 \%)$ & $80(17.8 \%)$ \\
\hline $50-49$ & $360(19.4 \%)$ & $449(24.6 \%)$ & $84(20.3 \%)$ & $102(22.7 \%)$ \\
\hline $60-69$ & $444(23.9 \%)$ & $396(21.6 \%)$ & $95(23 \%)$ & $96(21.4 \%)$ \\
\hline $80-79$ & $429(23 \%)$ & $384(21 \%)$ & $25(6 \%)$ & $105(23.4 \%)$ \\
\hline total (100\%) & $376(20.2 \%)$ & $128(7 \%)$ & 414 & $26(5.8 \%)$ \\
\hline
\end{tabular}

* NCRS - National Cancer Register of Slovakia

Table 4. Comparison of geographical distribution between Slovak HBOC suspected families and NCRS registered breast and ovarian cancer

\begin{tabular}{lcccccc}
\hline & $\begin{array}{c}\text { HBOC } \\
\text { suspected } \\
\text { families (\%) }\end{array}$ & $\begin{array}{c}\text { BRCA1/2 } \\
\text { positive families/ } \\
\text { carriers }\end{array}$ & \multicolumn{2}{c}{$\begin{array}{c}\text { Female Breast Cancer Cases } \\
\text { (NCRS*) }\end{array}$} & \multicolumn{2}{c}{$\begin{array}{c}\text { Ovarian Cancer Cases } \\
\text { (NCRS*) }\end{array}$} \\
\cline { 5 - 8 } & $46(35,4 \%)$ & $5 / 8$ & $2000(\%)$ & $2001(\%)$ & $2000(\%)$ & $2001(\%)$ \\
\hline Bratislava & $50(38.5 \%)$ & $7 / 29$ & $682(36.7 \%)$ & $677(37 \%)$ & $142(34.3 \%)$ & $171(38 \%)$ \\
\hline Western Slovakia & $54(26.1 \%)$ & $8 / 14$ & $851(45.8 \%)$ & $836(45.8 \%)$ & $202(48.8 \%)$ & $203(45.2 \%)$ \\
\hline $\begin{array}{l}\text { Central and Eastern } \\
\text { Slovakia }\end{array}$ & 130 & $20 / 51$ & 1858 & 1827 & 414 & 449 \\
\hline Total (100\%) & $30.2 \%)$ & $70(16.9 \%)$ & $75(16.7 \%)$ \\
\hline
\end{tabular}

* NCRS - National Cancer Register of Slovakia

The age distribution of breast and ovarian cancer onset in the study group is shown in Table 2. Onset of breast cancer in the HBC group was $9(8 \%), 30$ (26.5\%), $52(46 \%), 20(17.7 \%)$ and $2(1.8 \%)$ for age intervals <29, 30-39, 40-49, 50-59, 60-69, respectively. The highest proportion of onset was observed within the $5^{\text {th }}$ decade of life (interval 40-49), while NCRS reports a ten year later age of disease 
onset for sporadic cases (see Table 3). The age distribution of index cases in 17 ovarian cancer families were 1 (5.9\%), $13(76.5 \%)$ and $3(17.6 \%)$ for intervals 30-39, 40-49, 50-59, respectively. In contrast with the group of $\mathrm{HOC}$ families, where about $3 / 4$ of all cases were diagnosed again in the 5th decade, more than half of the unselected ovarian cancer cases developed disease by the age of 60 years.

To study the geographical distribution of hereditary breast and/or ovarian cancer we have divided Slovakia into three parts: 1. Bratislava including the suburban area, 2. western Slovakia, 3. central and eastern Slovakia (Table 4). The incidence of HBOC suspected families approximately follows this geographical distribution, with a small increase in the western part of Slovakia. Families with detected BRCA $1 / 2$ mutations, however, are almost equally distributed in all three regions.

\section{Discussion}

In this report we focused on $\mathrm{HBOC}$, age and geographical distribution of 130 suspected families from probands diagnosed with disease between and including the years 2000 to 2004 . To date, no study addressing the presented features of Slovak HBOC suspected families with BRCA1/BRCA2 pathogenic mutations has been reported. Our Department of Cancer Genetics at the Cancer Research Institute in Bratislava was the first laboratory to provide molecular analysis for hereditary breast and/or ovarian cancer for families, and has state-wide relevance.

We used the incidence, age and geographical distribution of unselected breast and/or ovarian cancer patients from NCRS to compare with the data from the index cases of HBOC suspected families. NCRS was established in 1976 and provides a quality database of incidence and mortality of all cancer types in our country. To date, 250 members of 130 HBOC families have been screened for mutations in BRCA1/BRCA2. Of these 130 kindreds, 20 families with pathogenic alterations have been identified. Identification of $15.6 \%$ BRCA1/BRCA2 positive families correlates with mutation rates found in other European high-risk populations [10]. In total, 51 mutation carriers from 91 available family members were detected. Similar to the observations from mutation screening of women with familial or early onset breast and/or ovarian cancer in the Czech Republic [1 1], the majority (17.5\%) of disease-predisposing BRCA1/BRCA2 alleles were identified in a group of highrisk HBOC families (Table 1).

The relative contribution of $B R C A 1$ and $B R C A 2$ appeared to be unequal and most of the pathogenic mutations were found in the BRCA1 gene (see Table $1)$. It has to be noted that our screening strategy including the first 16 exons of BRCA2 and the remaining exons of the gene needs to be analysed. Although the experimental approach used (a combination of SSCP, HDA and DNA sequencing) has a very high detection rate, some loss-of-function mutations and all large genomic rearrangements were not capable of being detected using this strategy. Such rearrangements are believed to be responsible for 10\% to $15 \%$ of BRCA1 inactivating mutations [12].

Our findings confirmed that early age of breast and ovarian cancer onset (before the age of 50) is one of the best criteria for assigning the family as hereditary breast and/or ovarian cancer kindreds (Table 2). According to improvements in the overall education and prompt application of results from BRCA1/BRCA2 mutation screening, one can predict that the identification of women at risk of disease will shift to an earlier age and also to a lower stage of disease by virtue of active prophylactic screening measures.

When we look at the distribution of $\mathrm{HBOC}$ suspected families within the three regions of Slovakia, differences in the frequencies of families in particular areas can be seen. This is most likely caused by historical, industrial and information-level distinctions between the different geographical regions that are manifested as different frequencies of kindreds with proven mutations in BRCA1/BRCA2. The largest difference is primarily between western (which includes the capital, Bratislava) and eastern parts of the country. The change in $\mathrm{HBOC}$ frequency can be explained by the decreasing number of hospitals with departments of clinical genetics from the western to the eastern territories of the Slovak Republic. That therefore best explains the number of $\mathrm{HBOC}$ suspected families from these regions that did not appear to correlate with the overall distribution of unselected breast and ovarian cancer cases reported by NCRS.

\section{Acknowledgements}

We would like to thank all the medical geneticists and clinicians from the whole of Slovakia for the recruitment of patients for genetic analysis, especially Dr. Ilencikova, PhD. and Dr. Bella from the National Cancer Institute, Bratislava. Work at NCRS by Prof. I. Plesko, PhD., is much appreciated. This work was supported by Grant No. 117/0214/2001 from the VEGA grant agency of the Slovak Republic and by project No. 2003SP 5102808 00/028 0801 from the national programme 'Use of Cancer Genomics to Improve Human Population Health'. 


\section{References}

1. Ford D and Easton DF. The genetics of breast and ovarian cancer. Br J Cancer 1995; 72: 805-812.

2. Struewing JP, Hartge P, Wacholder S, Baker SM, Berlin M, McAdams M, Timmerman MM, Brody LC and Tucker MA. The risk of cancer associated with specific mutations of BRCAl and BRCA2 among Ashkenazi Jews. N Engl J Med 1997; 336: 1401-1408.

3. Antoniou A, Pharoah PD, Narod S, Risch HA, Eyfjord JE, Hopper JL, Loman N, Olsson H, Johannsson O, Borg A, Pasini B, Radice P, Manoukian S, Eccles DM, Tang N, Olah E, Anton-Culver H, Warner E, Lubinski J, Gronwald J, Gorski B, Tulinius H, Thorlacius S, Eerola H, Nevanlinna H, Syrjakoski K, Kallioniemi OP, Thompson D, Evans C, Peto J, Lalloo F, Evans DG and Easton DF. Average risks of breast and ovarian cancer associated with BRCA1 or BRCA2 mutations detected in case Series unselected for family history: a combined analysis of 22 studies. Am J Hum Genet 2003; 72: 1117-1130.

4. Rebbeck TR, Couch FJ, Kant J, Calzone K, DeShano M, Peng Y, Chen K, Garber JE and Weber BL. Genetic heterogeneity in hereditary breast cancer: role of BRCA1 and BRCA2. Am J Hum Genet 1996; 59: 547-553.

5. Greene MH. Genetics of breast cancer. Mayo Clin Proc 1997; 72: 54-65.

6. Meijers-Heijboer $\mathrm{H}$, van den Ouweland A, Klijn J, Wasielewski M, de Snoo A, Oldenburg R, Hollestelle A, Houben M, Crepin $E$, van Veghel-Plandsoen $M$, Elstrodt $F$, van Duijn $C$, Bartels $C$, Meijers C, Schutte M, McGuffog L, Thompson D, Easton D, Sodha N, Seal S, Barfoot R, Mangion J, Chang-Claude J, Eccles D, Eeles R, Evans DG, Houlston R, Murday V, Narod S, Peretz T, Peto J, Phelan C, Zhang HX, Szabo C, Devilee P, Goldgar D, Futreal PA, Nathanson KL, Weber B, Rahman N, Stratton MR and CHEK2-Breast Cancer Consortium. Low-penetrance susceptibility to breast cancer due to $\mathrm{CHEK} 2\left(^{*}\right) 1100 \mathrm{delC}$ in noncarriers of BRCA1 or BRCA2 mutations. Nat Genet 2002; 31: 55-59.

7. de Jong MM, Nolte IM, te Meerman GJ, van der Graaf WT, Oosterwiik JC, Kleibeuker JH, Schaapveld M and de Vries EG. Genes other than BRCA1 and BRCA2 involved in breast cancer susceptibility. J Med Genet 2002; 39: 225-242.

8. Wagner T, Stoppa-Lyonnet D, Fleischmann E, Muhr D, Pages S, Sandberg T, Caux V, Moeslinger R, Langbauer G, Borg A and Oefner P. Denaturing high-performance liquid chromatography detects reliably BRCA1 and BRCA2 mutations. Genomics 1999; 62: 369-376.

9. Ciernikova S, Tomka M, Sedlakova O, Reinerova M, Stevurkova V, Kovac M, Cente M, Ilencikova D, Bella V and Zajac V. The novel exon 11 mutation of BRCA1 gene in a high-risk family. Neoplasma 2003; 50: 403-407.

10. Venkitaraman AR. Cancer susceptibility and the functions of BRCA1 and BRCA2. Cell 2002; 108: 171-182.

11. Foretova L, Machackova E, Navratilova M, Pavlu H, Hruba M, Lukesova M, Valik D. BRCA1 and BRCA2 mutations in women with familial or early-onset breast/ovarian cancer in the Czech Republic. Hum Mutat 2004; 23: 397-398.

12. Unger MA, Nathanson KL, Calzone K, Antin-Ozerkis D, Shih HA, Martin AM, Lenoir GM, Mazoyer S and Weber BL. Screening for genomic rearrangements in families with breast and ovarian cancer identifies BRCAl mutations previously missed by conformation-sensitive gel electrophoresis or sequencing. Am J Hum Genet 2000; 67: 841-850. 